\title{
Negotiation Strategy between the Two Koreas: With Emphasis on Politico-Military Affairs
}

\author{
LEE, Dalgon \\ Assistant Professor, Graduate School of Public Administration, Seoul National University
}

\section{Introduction}

Global detente seems to be a trend in the near future. The exorbitant German reunification, expecially, has instigated South Korea's expectation for Korean integration. However, North Korea reportedly decided to return to their backward policy and took measures to forbid softening of their socio-political system: that is, they remain one of the world's most closed society. Although there is a hint of forward change, the behavior of the North Korean elites cast a gloom over the future of the lives of all Koreans.

In the southern part of the peninsula, changes are occuring in the military section. The U.S. government has set plans to withdraw some portion of the U. S. Forces stationed in Korea. Implementation of the plan will be dependent on the strategic situation of the Far East. Besides the reduction of the U.S. forces in Korea, the Korean government began to seriously consider arms control. Such a change of attitude was signaled by the speech of President Rho in the U.N. General Assembly last year.

Based on the record of dialogues and the tension-reduction measures carried out in the past 30 years, we find a sharp contrast between the two sides in terms of intention and strategy. ") Such contrast will remain even in the near future. The negotiations between the two sides, involving various issues, turned out to be ineffective because the negotiators did not seek potential 'mutual gain': the intention of the authorities was a one-sided victory or domination.

For this paper, a long-term strategy for politico-military negotiation was envisaged with special concern on the asymmetry and the limited intention of both sides seeking mutual gain. Negotiations can only succeed as a policy tool when the parties involved have real intentions to resolve protracted conflicts through peace and through an attitude of compromise for increased joint gain. Therefore, any strategy developed for only one party has limited utility. Therefore, the

The Korean Joumal of Policy Studies Vol. 5 (1990), 25-44 
writer tries to take a symmetrical prescriptive approach with policy recommendation for the South Korean government.

\section{Rhetoric and Reality}

\section{Idle Run with a Squeaky Noise}

There has been numerous exchanges of formal proposals to exploit the protracted conflict for their own purposes between the two Koreas. However, there has been a few serious responses from each side to develop the other sides' offers to build a bridge for mutual cooperation. Each side has made use of their proposal as a propaganda for peace offensive or internal use to suppress the mass' demand for political freedom, or to mobilize people for national purposes. Recently there seems to be a negotiation warfare between the two sides. Some offers do not have any implementation plans and contradict each other.

Among numerous dialogues, the 7.4 Joint Communique was one of the landmarks of Korean unification history but only as a matter of form. The two Koreas reached seven points of agreement: 1) three principles of unification, such as, independence from and noninterference by foreigners, peaceful way of unification, and the acknowledgment of importance of national unity over the differences of ideology and social system; 2) disavowal of propaganda and military provocation; 3) diverse exchanges; 4) Red Cross talks; 5) installation of a direct telephone line; 6) establishment of a South-North Coordinating Committee; and 7) a solemn promise to carry out above agreements faithfully. The agreements achieved at least three things: (1) it set a guideline for unification process; (2) it set up an institution for effective working relationship; and (3) it developed an incremental approach based on neofunctionalism.

With this communique, the expectation for tension reduction suddenly rose. There had been mutual visits to Seoul and Pyongyang, and the South-North Coordinating Committee had had many meetings. However, the results were not effective in building confidences: the two sides lost their golden opportunity. The real intention of North Korea for reaching such an agreement turned out to be for military agression. They built underground infiltration tunnels for military purposes. In the Fall of that year, South Korea initiated 'Yushin' (Oppressive Political Renovation) and tried to oppress any political opposition to the Park's regime. Although the activities of the Coordinating Committee lasted until the late 1970's, the truthless attitude of both sides hindered such working relationship from functioning properly.

There had been five channels of dialogue between the two Koreas: Red Cross, economic, sports, parliamentary talks, and the meeting of high-level authorities which concentrated on plitico-military affairs. North Korea always suspended 
talks when "Team Spirit," the U.S.-R. O. K. joint military exercise, was announced. Deteriorating peace offenses came from North Korea when they believed that it was a good opportunity to take the initiative.

Apparently there had been 10 interactions each month between the two Koreas in various forms in the late 1980's and early 1990. Also, there is slight evidence that the North Korea is hesitant in proposing dialogue when South Korea faces internal problems, such as, political upheaval, economic difficulties, and etc. At the same time, they dexterously developed plots to create dissensions among various factions in South Korea.

Just after the Korean War they proposed arms control measures, whose contents did not change for the past 30 years. They demonstrated stubborness and inflexibility in negotiation proposals vis-a-vis South Korea. Recently, North Korea proposed unprecedented arms control measures and even became cooperative in preparing the meeting of high-level authorities to be held this Fall. In this meeting, politico-military matters, such as, arms control, and the U. N. seat, will be discussed. Pan-Korean Rally does not seem to be successful, but it is interesting to note that they began employing Korean residents abroad as a good bridge for communication. The role of a third party needs to be emphasized in building working relationships with North Korea.

In addition to the interactions mentioned above, there is another negotiation which is oblivious to both the public and the policymakers: that is, the Armistice negotiations. The meeting of the Military Armistice Commission has been held about 450 times. The Commission is entrusted with the mission of "settling" through negotiations reported in violations of the Armistice Agreement. However, many paragraphs of the Agreement were suspended by both sides without justifiable reasons. Numerous incidences of violation have been recorded and the activities of Neutral Nations Supervisory Commission had been extremely limited. Although the meetings may seem fragible at times, hostilities have remained suspended for the past 37 years, mainly because both sides have had a common interest in maintaining the status quo in Korea. ${ }^{2)}$ This channel can be used when implementing any arms control measures.

When compared to such frequent interactions with numerous proposals for more than $\mathbf{4 0}$ years, the performance realized during the periods are really disappointing. The Red Cross talks realized a modest success in terms of direct interaction of the people and exchanges of some commodities. North Korea proposed to help South Korean flood victims by sending rice, fabric, cement, and medicines in 1984. South Korea decided to accept those commodities with the confidence that the acceptance would not damage South Korea's presitige. Following the exchange, a remarkable event in the history of the Korean unification occurred in the Fall of 1985: about 50 of the dispersed families visited their hometowns with equal number of perfnrming artists and thirty reporters. ${ }^{3)}$ 
Beginning in the early 1980s, North Korea selectively allowed Korean residents abroad to travel to North Korea and to interview the residents. Recently there have been a couple of cases where members of the general public, who have not received permission, secretly entered North Korea; and several North Korean students abroad sought refugee in South Korea.

In South Korea, several groups of people demanded that the government give permission to visit North Korea. Public opinion is divided, and the government is pushed to the corner for taking measures. The South Korean government declared several measures enabling wide contacts; President Roh took initiatives, such as, the July 7, 1988 Special Speech and the July 20, 1990 Exchange Proposal. However, there is still strict control of free contacts by the South, not to mention the North. North Korea rigidly control domestic travel as well as foreign travel in order to prohibit permeation of free ideas. Domestic information-flow among the mass seems to be strictly limited, resulting in no inspirational changes. Also, information of North Korean society is very limited to the outside because of the nature of their closed society.

Even experts, for example, cannot estimate how many of top ranking officials read foreign newspapers, nor can they estimate the size and the configuration of technocrats. Information flow in a society like North Korea will play a key function in social changes. In an absolute monarchy, diverse information among top decision makers is a crucial factor which make them look into other alternatives. Limited information circulation help North Korea keep its status quo, and lack of accumulated information regarding the North Korean society hinder South Korea in formulating a good strategy for unification: nobody can estimate the future changes of the society with reasonable margins.

In the North, the conjunction of the succession from father to son with the need to revamp an economy, which is falling behind in the race for supremacy over the South, produces idelogical strains. The result, however, could be a more technologically oriented one resulting in a less isolated society, if the economic technocrats have their way and the oppressive personality cult is scaled down after the Kim era. ${ }^{4)}$ Still, dialogue with the South is a tactical manoeuvre, and not a real policy change. The North not only does not accept the division, but also does not recognize the legitimacy of the South. The two Koreas increased nonviolent contacts, but are still divided: systemic, ideological and value differences have become firmly fixed.

\section{Problems of Past Interactions}

As summarized in the previous section, numerous interactions turned out fruitless. One of the most crucial reasons for such stalemate came from international political conditions. Confrontation between the Super Powers in the cold war era 
left no room for autonomy and cooperation in the Korean peninsula. Gorbachev's initiatives, which is coupled by Bush's "status-quo plus" and "beyond containment" policy, made a good opportunity for tension-reduction and mutual cooperation between the two Koreas. As international environment changed favorably, the two Korean governments must switch their existing policy of confrontation and domination toward building a national welfare state in the near future. At this stage, we must find poblems of past policy, so as to develop a creative strategy for peaceful reunification with proper procedures.

First, neither of the two Koreas did not succeed in building mutual trust. North Korea set up their policy goal to "liberate the South". Kim Il-sung set forth a fomula that called for the "three revolutionary capabilities" to achieve national unification and a military strategy of the "four major military lines" in early 1960s. Although there are minor changes of tactics in order to adapt to specific cases, there are no hints of changes in the real goal of their policy. South Korea's unification policy had been less clearly defined than the North's. Because economic foundation had been weak in the 1960s, economic development took first priority and unification policy was put aside for two decades. Beginning in the early 1980s, South Korea began to have psychological confidence in competetion vis-a-vis North Korea. They tried to change their defensive role in the North-South interactions toward a positive one: the South Korean government began to formulate comprehensive unification plans.

Although both sides have been engaged in intermittent series of dialogues, the differences in goal and approach are so deep that there is no immediate prospect of program in tension-reduction and exchanges.

South Korea states that they do not intend to dominate nor plan to irritate North Korea: they are ready to help the North open up or reform their system. In reality, however, it is still hard to find any concrete measures to help them with the way that the North finds acceptable. Both sides clearly say that they do not have any intention to dominate the other. However, the problem of lack of mutual trust cannot be solved by exchange of statements which the other party considers as propaganda.

Second, there is a mismatch of strategies: the rigidity of strategy in the case of North Korea and the lack of consistent strategy in the case of South Korea. North Korea took a consistent strategy: to exploit North-South negotiations as an instrument of realizing their political goal. This type of negotiation is an orthodox "positional negotiation." They stick to their original position and do whatever it takes to help them realize their goal. South Korea, as mentioned above, did not have a positive strategy at the earlier stage of dialogues. Recently, South Korea made a comprehensive unification policy and tried to coordinate unification policy with national security policy. However, South Korea has had difficulties in switching from previous confrontational strategy toward the coop- 
erative strategy which enables mutual gains with principles. The principles may include rational judgment of joint gain and good working relationship. So called "principles negotiation" should be taken by both sides in order to solve the protracted conflict through bargaining. ${ }^{5)}$ Without being based on objectivity and rationality, it is very hard to proceed peace process through negotiations.

Third, both sides tend to abrogate previous agreements. The Armistice Agreement and the July 4, 1972 Joint Communique are very important to understand for Keeping peace in the Korea peninsula. Specifically, the 7.4 Communique set keeping peace in the Korean peninsula. Specifically, the 7.4 Communique set forth basic principles in approaching unification. Because North Korea had intended other things than agreement, they violated the spirit as well as letter of the agreement.

plan. This very fact implies two things: (1) unification issue is used for domestic political use and (2) such change cannot keep consistency nor continuity. Although the sixth Republic has a balanced and comprehensive unification plan, it is doubtful that it will become a long lasting plan until unification. Unification plan of both sides usually do not have any room for negotiations. A true unification plan must be designed through negotiations with a step by step approach.

Both sides forget very valuable agreements made previously, and start again and again. Lack of continuity in negotiation means that the North-South negotiation is not on the normal track. The Armistice Agreement and the 7.4 Joint Communique are really good agreements in solving politico-military affairs. Politico-military confidence building can start by finding ways to carry out the spirit of the previous agreements.

Forth, decision-making structure and process of each side create problems for flexible negotiations. In relation to North-South interactions, decision power seems to rest in the hands of a couple of people on both sides. Decisions are made at the highest-level of authority and implementation is very strictly monitored. North Korea lacks flexibility in decision making and implementation, so it is rather hard to adapt to the changing environment. Also, their chain of actions that are based on "Juche" cannot be changed casily.

On the other hand, in South Korea, policy making structure and process should have been improved, since the configuration of unification policy is not well integrated in all of the government policy making process. Still, defense policy and security policy circles dominate in the North-South related policy making system. Implementation is supposed to be handled by ordinary bureaucrats with close control. There are experts of interactions on both sides, and because they do not have discretion to the fullest measure, dialogues are actually carried out by agents for the public, and real decisions are made behind the scene. 


\section{Searching for a Strategy}

\section{Game Theoretic Approach}

There have been many theoretical models which try to capture the relationship among conflicting parties with game theoretic perspective. Out of the several models that deal with protracted conflicting situations, Prisoner's dilemma seems to best model the interactions between the North and South Korea as a series of moves that reflect the policy choices of the two governments. Three assumptions underline the model: the two sides are rational actors; each government can estimate the benefits and costs of alternative action programs; and the two parties perceive the same game.

If North Korea analyzes the present North-South relationship and see a Prisoner's Dilemma payoff structure, she will find it difficult to enter or maintain a negotiated agreement. She will see advantages in deceiving the South and breaking the previous agreements to achieve some perceived unilateral advantage. If the South pursues identical logic, both may violate any agreement. The paradox of the Prisoner's Dilemma lies in the fact that both sides would have been better off had they cooperated, but the logic of the individual leads them away from cooperation.

But fortunately, South Korea began not to take the same logic of behavior North Korea took: The South did not try to overthrow the North Korean regime, and maintained peaceful approach toward unification. This type of approach seems to appear as adaptive or negative to the aggressive attitude of North Korea. This asymmetry of strategy is a very important element that will help the NorthSouth relationship out of the Prisoner's Dilemma. Only by taking a different logic than the one North Korea follows, South Korea can realize the goal of her unification policy on the basis of her own pace and plan.

Until mid 1970's during which North Korea believed that their national strength exceeded that of South Korea, they were likely to develop their interaction strategy according to an iterated or repeated Prisoner's dilemma game model with an end. With that model in mind, the North Korean policy-makers would choose the road of domination and agression as the best strategy. ${ }^{(6)}$ The following explanation will help readers to understand the reason. If the two sides perceive the same end to the game, then each will perceive that, on the last play, their logical choice would be defection; therefore, on the second last play the logical choice must also be defection, and so on. When there is no fixed termination to the game, but only risks of termination, then the logical choice is less clear and depends on the risk, or on the value each player places on current payoffs relative to future payoffs. North Korea will not try to use military power or other 
unlawful measures if she thinks that the termination of confrontation cannot be realized with finite probabilities, or that if it is not possible to dominate the South within a forseeable length of time period. Because of the changing international environment and the economic gap of the two Koreas, North Korea seems to realize that it is impossible to overthrow the South Korea regime with military forces. South Korea must take advantage of this very point.

Robert Axelrod analyzed the Prisoner's Dilemma game and the relationships between superpowers and concluded that no single strategy is optimal. And he has suggested on a strategy which will generally fare better than any others over the long term. ${ }^{7)}$

This model is well suited for the situation when the value of future payoffs is important and when the strategy of the other is not known in advance. He calls this strategy "tit-for-tat." According to his strategy the South starts with cooperative proposal or action on the first interaction, and then duplicates whatever the North did on the previous move. This strategy has four properties: (1) cooperation as long as the North cooperates; (2) punishment when the North defects; (3) forgiving the behavior of the North beyond a single move; (4) and making the North easily perceive a pattern and understand the consequences of their actions.

This model, of course, has problems in several aspects. However, the model points out the importance that cooperative action must be made first by the party that tries to initiate peace process. South Korea should be an initiator since she has already planned to satisfy the needs of North Korca.

There are some chances of getting out of the North-South Prisoner's Dilemma game as analyzed above. Then, the South must substantiate such a process by warmly responding to the proposals made by the North. The warm response shown recently by the South seems to be a good opportunity to start the strategy "tit-for-tat." In order to emphasize initial coopcrativc action, the author wants to link the strategy "tit-for-tat" with the strategy of unilateral reward in the following section.

\section{Tit-for-Tat Strategy and Unilateral Reward}

As mentioned in the previous section, there is a possibility for the two Koreas to escape the wearisome Prisoner's Dilemma game. Also, the strategy "tit-for-tat" presents a policy direction for the South Korean policy-makers at this stage of development. Because South Korea surpasses North Korea in many aspects, North Korea is in a delicate position: they must seriously consider expected returns from South Korea when they harass South Korea. South Korea, on the other hand, must prepare effective reward and penalty in accordance with the expected actions North Korea will take. Especially, South Korea should work 
hard in the areas of crisis management. As shown in the case of Rangoon or KAL incidents, South Korea did not meet the situation positively. KumKangSan-Dam and the rumor of Kim Ill-sung's death, also, prove poor policy handling. Together with sanction and penalty for defection, the South must think about incentive or reward for cooperation from the North. The term "reward" is used here broadly to include positive incentives, following Louis Kriesberg's definition of rewards as positive sanctions, offers or grants to the adversary. It is made in anticipation of a reciprocating concession. ${ }^{8)}$ Here, the writer wants to emphasize the importance of reward in relation to the tit-for-tat stratégy.

There are a couple of cases in which the strategy of unilateral reward worked effectively in overcoming profound psychological barriers and produced a major transformation in protracted conflict relationship. One of the succesful cases was president Anwar Sadat's trip to Jerusalem in November 1977. Through such bold and risky trip, Sadat historically made a major turning point in the Arab-Israeli conflict. A psychological threshold has been crossed in the history of that conflict, moving the idea of recognition and peace between the adversaries into the domain of possible, the thinkable, and the imaginable.") Sadat's initiative and the ensuing peace process have demonstrated that the impossible is in fact possible and the unthinkable, thinkable. In the history of North-South conflict, the July 4, 1972 Joint Communique is of that kind. But the reponse from North Korea was not cooperative: they violated the agreement by making underground tunnel across the DMZ. Also, aids for flood victims and limited reunion of dispersed family members in 1985 were historical opportunities that should have been sublimated to unilateral rewards.

Those interactions might have made the possibility of ending the conflict more real, more palpable, than it had ever been before. These events created a sense of opportunity, hope, and excitement, which strengthened the motivation to move the process forward; but the internal problems of the two societies did not allow for such events to develop fully. The internal conditions of the two political entities have been one of the most serious limitations.

The North-South summit talks can make a historical turning point. However, we must recall the fabrication of the July, 4 Joint Communique which was a surrogate of the summit talks. In preparing for the Summit, the South must develop "unilateral reward" for the North, and that reward must overcome the bitter experience of the past agreements. A creative unilateral reward can be realized in the area of arms control. Since the Korean peninsula has quite different conditions with Europe or Germany, imaginable approach in arms control should be sought. This issue will be further discussed in Chapter IV of this paper. 


\section{Limitations of Strategic Models}

The problems with these rational models are well pointed out in text books. A theory is a theory, not easy to apply to real situations. It seems needless to mention in detail the shortage of general game theoretic model here. (1))

In addition to the general shortage of theoretic game model, the "tit-for-tat" strategy also has a couple of serious problems. If the South Korean policy-makers base the "tit-for-tat" model in devising unification strategy, then the unification policy can be the hostage of North Korea. In the middle of ongoing interactions it is hard to identify the "first move of cooperation." At the same time the strategy repeats cooperation-defection cycle simply. In order to avoid above problems, the South must take the initiative. It would be successful if the South finds a conspicuous "first cooperative" move, which is a kind of an historical unilateral reward. Also the unilateral reward must send messages of the true South Korean intention to North Korea.

The second problem with the "tit-fot-tat" strategy is the tendency that it may lead to downward spirals in relations, i.e., the negative spiral effect. South Korea, fortunately, has not retaliated to North Korea's provocations intentionally or unintentionally. The limited or partial retaliation may return the game to a positive spiral.

Furthermore, when the South plays the role of "the eldest brother," the chances of negative spiral seem minimal. Strategy of unilateral reward also has problems. First of all, it is extremely risky. Large changes often elicit equally large resistances, and may thus set the stage for a major setback externally as well as internally. This problem was realized in the case of the July, 4 Joint Communique: the North-South relationship deteriorated, and political oppression reached its peak just after the event. Unilateral initiative differed from those called for by Charles Osgood's GRIT strategy (graduated and reciprocated initiatives in tension reduction), which starts with small concessions and gradually builds on these. ${ }^{11)}$ While GRIT strategy allows reversible course of action, unilateral initiative constitutes an irreversible step which can be viewed extremely risky from a conservative point of view. Some rewards are considered fundamental concessions that cannot be recovered but which can become precedents.

The second problem with unilateral reward is that it may be ineffective or even counterproductive. Although it may set off an obligation to reciprocate on the part of the adversary, the adversary may not be interested in the offers since they prefer to continue the conflict. Also, when they think the subjective price of reciprocal concessions is higher than the benefit of the offer, they will take the reward and will not play.

The third problem with this type of strategy is that it is less capable of building 
consensus within a society. Because unilateral reward strategy jumps over several steps suddenly, it tends to sharpen some of the internal conflicts within each society. It creates unrealistic expectations about the other, and if the results are frustrated, the government is blamed for taking careless measures. It is apparent in the case of South Korea when we think of the diverse views on unification. There is still a large portion of people who believe that this is not an appropriate time to accelerate unification process. Such an avoidance tendency seems to dominate when a certain stage of exchange raises social anxiety and financial burden. The proponents of such initiative are vulnerable to the critics' charges that they were endangering the survival of the nation and contributing to disunity.

\section{A Framework for Better Policy}

\section{National Consensus Building}

Almost every negotiation is composed of four phases: preparation(prenegotiation), bargaining, agreement, and implementation. Although these phases are not separated and often carried out simultaneously, it is helpful to identify different activities which are essential in each phase. ${ }^{12)}$ Here, the writer wants to emphasize the importance of the preparation stage. The politico-military negotiation will determine the peace process and the nature of reunification. The proposals exchanged between the two Koreas have not yet been paid adequate attention.

Policies involving politico-military negotiation are formulated within the government circle. The structure and process of policy-making should be improved in order to formulate a creative policy and be sensible to diverse public opinion. Although surveys found that people took growing interests in unification, there is actually no passages to channel their view into policy-making processes. This type of policy-making can be called an "inside initiative model," and it will raise problems of legitimacy in a civil society. Sometimes very attentive public which include "dispersed families" and anti-government organizations, raise issues, but the policy-making system simply ignores such demands. The government should realize that one of its roles is coordination or compromise of extreme views, and several extreme cases, such as, Reverend Moon Ik-Hwan, Assemblyman Suh Kyung-Won, and Student Im Su-Kyung, gave a great shock to the so.ciety.

The government still does not realize the importance of effective public relationship regarding North-South negotiations. There are still serious cleavage in unification approach between the so-called radical groups and the government. Although students' protest against the government approach is related to internal political affairs, fragmented public opinion should be overcomed before carrying 
out negotiation with the North. Open discussion seems to be one of the most urgent thing for the convergence of public opinion, information should be dispersed and ideas exchaged without restriction. This becomes critical when South Korea plans to implement the "tit-for-tat with unilateral reward" strategy because the strategy often sharpens internal coflict.

\section{Consistent Policy Development}

Policies concerning the politico-military matters are formulated within several Ministries, and members of policy-making groups are diverse in their ideologies, backgrounds, information, and knowledge; however, the institutional arrangement is not so favorable to search for a creative policy option. Those institutions include the National Security Planning Board, the Ministry of Foreign Affairs, the Ministry of Defence, the National Unification Board, and related Offices of the President. Some of the staffs are in military uniform and they are not so confident of the South Korean military capability and very dubious of the North Korean intention of negotiation. Still, many of them believe that the North Korean policy-makers take advantage of negotiations as a mechanism of hiding their hostile activities. They approach strategically to cultivate cooperation with the North.

The experience of the Korean $W$ ar and past records of repetitive hostility and deceit made the South Korean policy-makers distrust any North Korean proposal. In addition, policy-makers who are familiar with the North Korean inner circle and their attitude toward unification instinctively became negative to North Korean offers. These tendencies cannot be blamed. While such conservative attitudes may help reduce risks, this kind of attitude and mood in the policy-making circle may also hinder creative ideas to flow forth.

Many liberal sections of the society blame the government because it exploited the North Korean threat as a tool for oppressing democratic movement. Threat appeal in the repressive regime and which is officially recognized by the 6th Republic became a burden for the government to build national consensus. ${ }^{13)}$

For younger policy-makers with civilian background, several taboos the policy circle has had seem to hinder taking steps forward. They are restricted in getting useful information and they think that there are other core groups of people who initiate and decide policies from different perspectives.

There are inconsistencies and discontinuities in the area of security and/or unification policy. The writer is very much concerned about appearing antecedent regarding the conditions of groupthinking. There are some evidences of symptoms of groupthinking although they are not so sufficient. Some members of the policy circle are cohesive in ideology and background, but there is a lack of tradition of impartial leadership, and often a lack of norms requiring methodical 
procedures. These characteristics help promote concurrence-seeking tendency. ${ }^{14)}$ The present decision-making system can be improved and symptoms of groupthinking can be reduced if the government encourages diverse voice within the decision-making circle as well as public discussion to a certain extent.

In addition, decision-making structures should be rearranged to offset insulations, and "devil's advocate" can be a safety device to offset leadership bias. Specifically, the narrow perspective each agency has can be enlarged when the leader tries to keep the atmosphere of free discussion. In that respect, the present system needs to be improved: the National Security Council seems to be a good institutional candidate for overcoming present shortages. Within the framework of the Council, the Unification, Defense, and Foreign Policies must be coordinated, and the Council should be supported by a group of policy analysts. Members of the group should include elite bureaucrats from related agencies, civilian experts, and military personnel.

In order to build a consistent security policy, the Minister of the Board of National Unification should become a member of the Council, and the numbers of participants should be reduced for adequate discussion and crisis management: the present number of participants are more than 10. Also, the present arms control organization should be enlarged with higher official status. Arms control issue should be discussed in the Council with special reference to the unification policy.

\section{The Highest Priority on Arms Control}

South Korea has spent more than $5 \%$ of its GNP in the defense sector. In the case of the North, more than $20 \%$ of GNP goes to defense. With these resources usde up in military buildup, there must be a serious limitation in improving the welfare standards of the people. Fortunately, both Koreas were rather successful in escaping from hunger in a relatively short period of time; but during such a process, North Korea faced serious bottleneck due to the nature of its politicoeconomic system and heavy defense burden.

South Korea has potentials of becoming an advanced country in the near future. However, she is facing serious problems from many areas. Domestic politics still remain at a clumsy level. Although military rule seems to fade out incrementally, political parties and the Parliament has not played up to their expected roles. In addition, the cleavage between Eastern and Western regions had been seriously hardening. The rising expectations of the people for high level of welfare are still problematic due to inadequate resources.

In order to overcome family-centered egoism which is now rampant in the urbanized areas of South Korea, it is urgent to cultivate community spirits. It is the education system that brings up the younger generation. A huge amount of 
economic resources are needed in upgrading the education system. Furthermore, thechnology development and investment for the basic science is urgent to sustain cconomic development. Large scale investment is necessary for preserving the national environment. With present portion of the GNP in the defense sector, it seems very hard for South Korea to solve the problems raised in the above.

Every country which competes with South Korea tries to reduce military burden and/or has far less burden for defense. Besides, tension reduction in the military area must be realized during this era of post cold war period. It is apparent that the North did not change the basic policy of communizing the whole Korean peninsula. They even consider North-South dialogue as a means of overturning the South Korean system, and to make things worse, they skillfully move in every turn of negotiation; they stick to their original position. However, North Korean policy makers seem to believe the necessity of arms reduction. The necessity for taking such a policy direction is coming from many sides: economic slackness that has lasted longer than decades; changes of international environment, and indirect pressures from outsides, to mention a few. Because of the nature of their social system, however, it is not easy to find any measure which can make South Korea genuinely trust them. The problem is that the North cannot raise the degree of the social transparency without changing the societal system.

There may be two areas of potential reforms which North Korea can take: (1) opening up their system only for enlarging international trade; and (2) arms control. They cannot take the road of internal democratization and introduction of private ownership in the near future. These are the very differences between North Korea and other Eastern Euopean socialist countries, including Soviet Union.

The Sot th Korean policy-makers basically follow the model of the European arms control approach. They emphasize the importance of confidence building measures(CBMs) before getting into any substantive arms control and/or reduction measures. It can be called 'CBM-first, arms control-second' policy. For more than 30 years, North Korea has proposed arms size reduction to 100,000 and the withdrawal of all foreign troops. As they did in other fields of negotiation, North Korea took a "once and for all" approach to arms control, too.

However, recently they seem to be changing their unique negotiation style: they have offered a more flexible arms control proposal on May 31, 1990. Although they did not clearly mention the CBMs, they let in several items of confidence building measures, such as, a hot line, prohibition of exercise larger than division forces, substantial demilitarization of DMZ, etc. Still, they do not take all the basic of the Stockholm confidence building measures. However, the recent development throws a light on the future of arms control in the Korean peninsula. 
In order to substantiate the mere proposals into real peace, the South Korean government took several meaures: it reorganized arms control-related agencies and prepared a government plan to be used in negotiation. At this stage, South Korea should think about the strategy tit-for-tat and strategy of unilateral reward explained above. South Korea had emphasized the importance of political confidence building before getting into military confidence building. The problem with this sequential approach comes from the fact that North Korea thinks the other way around. They approach political affairs very uniquely that the South cannot accept. This is another asymmetry. In addition, because they have not experienced changes in their political leadership they are not in a position to approach politics flexibly.

This is the reason why North Korea is hesitating in holding the summit talks South Korea earnestly seeks. The South Korean government wants to have the summit because that can be a real turning point and an opening break through. Also it is very helpful for enhancing the president's prestige. The South Korean government tries to link the meeting of high-level authority summit talks with the progress of affairs. The North Korean authorities, however, clearly hints that they do not want to have the summit unless any real progress is achieved in the meeting of high-level authorities. Although the summit talks can be considered as a unilateral reward from the South's perspective, the North is not in a position to consider the talks as a big incentive. They think that a singee combined $U$. N. seat and arms reduction are real rewards.

We are reminded that North Korea had emphasized military problems in the meeting of high-level authorities. Pivotal point for arms control is to open up further negotiations. Therefore the South Korean government must think about the preconditional position of political confidence building measures. The two Koreas cannot easily find any effective measures for mutual political confidence. Because both sides have serious porblems in domestic politics, it does not seem to be a good option to accelerate political integration. The two Koreas are very different from the two Germanies: economic bases are still very weak, ideological confrontation is keen, the experience of the Korean War is vivid, and both regimes have strong military nature.

Without changing the North's leadership stzucture, it seems very hard to change their party's political platform. When we think of the nature of their decision-making behavior, it seems plausible that they try to open up for increased foreign trade and carry out arms control holding their internal reform at the present speed. In sum, the writer would like to argue that exchange in term of economic goods and services as well as personal visits can go with military confidence measures side by side. Even the arms control measures can be pursued independently. In this approach, political matters, including political confidence building measures are not emphasized as the precondition for arms control; they 
can go simultaneously.

Kim Il-sung is 78 years old and has symptoms of myocardial infraction; he will phase out of the scene sooner or later. And Kim Jung-il seems to be in a weak position and does not have the charisma absolutely needed in ruling the totalitarian society. Kim Il-sung consciously plans to induce socio-political changes slowly. In this case South Korea should not try to influence the processes in North Korea by emphasizing political trust-building. South Korea can help such softening changes by the channels of trade and arms control.

When taking this policy direction, risk-conscious analysts are afraid of real progress in the arms control. Without solid verification measures, it is really not easy to proceed further. However, when South Korea and USSR can develop a good working relationship, verification can be carried out by International Technical Means of Monitoring. Also, arms control measures that guarantee simple verification can go first. For this purpose, the North Eastern Asian Conference can be a good mechanism to coordinate. A similar idea, i. e., measures taken by the two Koreas, Asian-Pacific Security Organization, which was aired by Soviet Foreign Minister, Edward Shevardnage, is a good option to pursue further.

More specifically, in this case, first steps in the arms control measures will include: (1) disclosure of arms-related information; (2) unilateral notification and invitation for observation of military exercise; (3) demilitarization of a part of DMZ; (4) backward deployment of partial forces from DMZ and so on. As well, the policy of withdrawal of the U. S. forces from South Korea can be linked with the measures taken by North Korea.

The first several measures can be easily implemented either unilaterally or with the help of the USA and the USSR. Because military exercise larger than a certain size can be monitored easily by both sides, the reliability of notification can be examined very easily. If both sides agree on this issue, it would be possible to take the above action without talking about the precondition of political trust-building. It will generate far reaching impacts on building trust and policy development. At least symbolic gesture should be initiated by the South by applying the "tit-for-tat" with unilateral reward strategy. Arms control, even if it is merely symbolic and minimal, will be considered a great joint gains or mutual reward from both sides.

The next step may need some support from the Neutral Nations Supervisory Commission. Because both Koreas now have diplomatic relation with the four countries of the Commission, the Commission will carry out on-site inspection activities effectively and in a balanced way. When both sides agree to operate the Commission according to the Korean Armistice Agreement, they can take advantages of the opportunity to resolve the protracted conflict more easily by revising the old agreements they had kept dead for a long time. The previous agreements made from the time of the Armistice, including the July, 4 Joint Communique, 
will function as a benchmark again in designing the Korean integration.

\section{Principled Negotiation}

Although there had been numerous negotiations between the two Koreas, peace process has been very slow. Even several exchanges realized could be viewed as strategic movements, and not as genuine progress in the peace process. At this stage of negotiation, it seems helpful to distinguish between substance and procedure of negotiation. Negotiation substance includes agenda of aroundthe-table negotiation, such as exchange of mail, arms control, U. N. seat, etc. Procedure involves relationship, i. e., building a working relationship or physical arangements for actual negotiations.

The North-South Negotiation is far from institutionalizing the communication channel: there is no stable, good working relationship in which the process helps to produce better substantive outcomes. It appears that the best strategy on process is to be unconditionally constructive; it is of unilateral reward. That is, South Korea should do these things, and only those things that are good for the relationship whether or not they are reciprocated. ${ }^{15)}$ Elements of good working relationship includes, purposive attitude, rational understanding, effective communication, honesty, persuasion, and acceptance, etc. Although it is still not easy to keep any principle which is accepted as rational, it seems urgent to be unconditionally constructive in procedual matters; but both parties can be tough on substantive issues.

In dealing with substantive matters, the author suggests so called principled negotiation or negotiation on the merits be taken as a strategy. ${ }^{16)}$ Principled negotiation is different from other negotiation strategies, especially positional negotiation, in the following points: (1) Separate the relationship from the substantive matters; (2) Focus interests or utility and not on subjective positions; (3) Generate a variety of creative alternatives before clinging to only one option each side prefers; and (4) Insist that the results be faced on some ojective standard. By leaning the merits of principled negotiation, the two sides will realize that the protracted conflict can be resolved.

\section{Concluding Remarks}

In this paper, the writer had tried to build a theoretic foundation for the constructive North-South negotiation. The "tit-for-tat" strategy with unilateral reward was suggested for the South Korean government to initiate. Because the present international environment is favorable, it is up to the two Koreas whether they can take advantage of the salient trend of the century. At this juncture, a consistent and productive policy development is urgent. 
The writer also argues that the arms control can go along with or even precede other exchange programs and political confidence building measures. As well, the arms control process might well be initiated by South Korea based on the strategy "tit-for-tat" with unilateral reward. In addition, several procedual and institutional improvements were suggested for cautious preparation.

\section{Notes}

1) North Korea still considers dialogue or negotiation as an instrument of their policy of communizing the whole Korean peninsula. South Korea, however, tries to build trust and a working relationship for communication and exchange of goods and personnel.

2) Lee, James M., "An Overview of Armistice Negotiations and Lessons Learned," Paper Presented to the Fifth Hwarangdae International Symposium, Nov. 3, 1989.

3) For the details, see " $A$ White Paper on South-North Dialogue in Korea" (Seoul: National Unification Board, 1989).

4) Brian Bridges, Korea and the West(London: The Royal Institute of International Affairs, 1986), pp. 90-92.

5) Principled Negotiation was suggested by Fisher, R., and Ury, W., Getting to Yes: Negotiating Agreement Without Giving In(Boston: Houghton Miffin, 1981). This is discussed in the Chapter IV in this paper.

6) The logic of taking this hostile strategy is explained in, Scott Brown, "The Superpowers' Dilemma: Can Game Theory Improve the U. S.-Soviet Negotiation Relationship?", Negotiation Journal, Vol. 2, No. 4, (Oct. 1986), pp. 371-374.

7) Robert Axelrod, The Evolution of Cooperation(New York: Basic Books, 1984), pp. 32-67.

8) Louis Kriesberg, "Social Theory and the Deescalation of International Conflict," Sociological Review(August 1984).

9) Herbert C. Kelman, "Overcoming the Psychological Barrier: An Analysis of the Egyptain-Israeli Peace Process," Negotiation Journal, Vol. 1, No. 3(July 1985), pp. 213-234.

10) The problem can be summarized as follows: (1) Dangers of abstract simplification, (2) Governments are not always rational actor, (3) Governments often cannot calculate payoffs objectively, (4) The player governments are often not playing the same game, and (5) There are ambiguous move and partisan perceptions.

11) Charles Osgood, An Alternative to $W a r$ or Surrender(Urbana: University of Illinois Press, 1962).

12) Randolph, Lillian, "A Suggested Model of International Negotiation," Journal of Conflict Resolution, Vol. X, No. 3, (1966), pp. 344-353.

13) For threat appeal by the past Republics, see, Cha, Keun-Bai, Persuasion Communication Theory (Korean), (Seoul: Seoul National University Press 1989), pp. 345-365. 
14) Janis, Irving L., (second ed.), Groupthink(Boston: Houghton Mifflin Company, 1982), pp. 174-276.

15) Roger Fisher, "What is a Good U. S.-Soviet Relationship-And How Do We Build One," Negotiation Journal, Vol. 3, No. 4(October 1987), pp. 319-327.

16) Roger Fisher and William Ury, Getting to Yes: Negotiating Agreement Without Giving In(Boston: Houghton Mifflin, 1981), pp. 15-98. 